\title{
Welfare Enhancing Collusion in a Service Provision Model
}

\author{
Evan Moore \\ Auburn University at Montgomery • Montgomery, AL \\ James Boswell \\ Booz Allen Hamilton • Washington, DC
}

\begin{abstract}
This paper provides a model of service provision with homogeneous goods that allows for welfare comparisons between firms engaged in Cournot-type competition and joint-profit maximization. An important factor in this analysis is the role of service provision on the demand for the product. We find that collusion can be social welfare enhancing in a static framework and show that under certain conditions both consumers and producers can benefit from collusion; this occurs if the number of firms in the market exceeds roughly 20.4 firms. Additionally, we present a collusive result that we have not found elsewhere in the literature.
\end{abstract}

\section{Introduction}

Much of the research on collusion finds that social welfare is maximized when firms are engaged in competition rather than collusion. This is particularly true for static models, with exceptions usually arising when the models are dynamic. Examples of increased social welfare when firms are colluding are often related to quality, advertising, mergers, or research and development related joint ventures (Cellini \& Lambertini, 2003; Deltas \& Serfes, 2002; Fershtman \& Pakes, 2000; Kamien, Muller, \& Zang, 1992; Verboven, 1995). ${ }^{1}$

Using a static modeling approach, this paper provides a model of service provision with homogeneous goods that allows for welfare comparisons between firms engaged in Cournot-type competition and joint-profit maximization. An important factor in this analysis is the role of service provision on the demand for the product.

Unlike other works, we find that collusion can indeed be social welfare enhancing in a static framework. We show that under certain conditions both consumers and producers can benefit from collusion; this occurs if the number of firms in the market exceeds roughly 20.4 firms. Additionally, we have not found a collusive result in any other work that is similar to the one presented in this paper.

Much of the remainder of the paper is based on a theoretical model involving mathematical derivations. We would like to briefly mention some aspects of the 
model and implications for the reader that is not interested in the technical aspects of the work. We assume that the firms are producing, or selling, a homogeneous good with an associated level of service. Our central result, the finding that collusion can be social welfare enhancing, rests on the assumption that firms can engage in service provision which has a cumulative effect on potential buyers. If the effect is sufficiently strong then this induces individuals, who were not previously purchasing the good, to buy the product. These consumers are known as marginal consumers in the economics literature.

While the product being sold is identical, with similar amounts of service provided by each firm in equilibrium resulting in similar costs of provision, the nature of the service provided may vary among the firms. Some information may be viewed as bundled with the product but only from a certain firm. For example, one firm may provide a handout containing product information, while another may provide a demonstration regarding usage, and yet another convenient location in the store to view or sample the product. ${ }^{2}$

It is also possible to view our findings with firms required to provide both identical types and amounts service provision in equilibrium. The results show that the returns to collusion are greater, with higher total service provision, with greater numbers of firms. This can be interpreted that the pervasiveness of the product, i.e. availability in prime locations within the retailers, encourages the marginal consumer to buy due to repeated viewings at various outlets. ${ }^{3}$

However, if the service provision of the various firms is not cumulative, i.e. a firm's sales are not positively affected by the increased service levels of another firm, then collusion results in each firm receiving and equal share of the monopolist's profit and does not result in increased welfare for consumers; the total surplus is constant under this setting with producer and consumer surplus remaining constant regardless of the number of firms in the market. The appendix contains an alternative specification of the demand function which reflects each firm's sales as a function solely of its service provision, rather than the total level of service. A brief discussion comparing these results with the model in this section is provided. ${ }^{4}$

Our results suggest that managers need to consider how service provision affects the demand for the product being sold. We focus our efforts on homogeneous, i.e. identical, products where the total service provision in the market affects demand and also provide an alternative model where the firm's, or retailer, service provision is not cumulative. While it is not surprising that collusion among firms would lead to higher profits in either setting, if demand is indeed affected by the total level of service provision then coordinated efforts regarding the services provided may en- 
hance not only producer surplus but consumer surplus as well. This could serve as a justification for trade or retail organizations and suggests that managers may want to participate in these groups.

The remainder of the paper is organized as follows. "The Model" presents the results of an n-firm model providing services in a market involving homogeneous goods. "Collusion and welfare comparisons" provides welfare comparisons between firms engaged in competition and collusion. "Conclusion" provides a summary of the findings.

\section{The Model}

Consider an industry of $n$ identical firms facing a market demand function of $Q(P, S)=S(A-P)$, where $Q$ is the industry output, $P$ is the output price, $S$ is the level of service provided in the market, and $A$ is a shift parameter corresponding to the intercept on a linear demand curve with $A>0$. This demand function is used by Boswell and Moore (2009), Hegji and Moore (2005), and Pepall, Richards, and Norman (2002). ${ }^{5}$ With this demand function increased service levels result in increased reservation prices and an increase in market size. Hegji and Moore (2005) note that, "...demand does not shift parallel with an increase in service but, rather, rotates around the price axis" (p. 135). This demand function is useful in cases where service is directly bundled to the product, such as product assembly or repair information. Alternatively, service could be viewed in terms of product display or other cases where service costs are incorporated into product price.

Total costs are a function of both service provision and production costs. Production costs are assumed to be at a constant marginal cost of $C$ and service, $s$, at a constant per unit cost of $\varphi$. We assume $s_{i}>0$ and $\varphi>0$. The total cost for firm $i$ is $T C_{i}=q_{i}\left(C+\varphi s_{i}\right)$. To ensure positive equilibrium output levels we assume $A>(C+\varphi s)$.

The market inverse demand function is:

$$
P=A-\frac{Q}{S} .
$$

where $Q=\sum_{i=1}^{n} q_{i}$ and $S=\sum_{i=1}^{n} s_{i}$. To simplify our notation in the following derivations, we define $Q_{j}=\sum_{k \neq i}^{n} q_{k}$ and $S_{j}=\sum_{k \neq i}^{n} S_{k}$.

Profit for firm $i$ is thus

$$
\Pi_{i}\left(q_{i}, s_{i}\right)=\left[A-\frac{q_{i}+Q_{j}}{s_{i}+S_{j}}\right] q_{i}-\left(C+\varphi s_{i}\right) q_{i},
$$


Maximizing (2) with respect to $q_{i}$ results in the reaction function

$$
q_{i}=\frac{\left(A-\varphi s_{i}-C\right)\left(s_{i}+S_{j}\right)}{2}-\frac{Q_{j}}{2}
$$

Maximizing (2) with respect to $s_{i}$ yields the relationship

$$
s_{i}=\sqrt{\frac{q_{i}+Q_{j}}{\varphi}}-S_{j} .
$$

In equilibrium the firms will have identical levels of quantity and service such that $Q=n q_{i}$ and $S=n s_{i}$. It follows that $Q_{j}=(n-1) q_{i}$ and $S_{j}=(n-1) s_{i}$. Substituting (3) into (4) and solving for $s_{i}$ in terms of $q_{i}$ results in

$$
s_{i}=\frac{q_{i}}{\sqrt{\varphi n q_{i}}} .
$$

Solving for $q_{i}$ in terms of $s_{i}$ gives

$$
q_{i}=\frac{n s_{i}\left(A-C-\varphi s_{i}\right)}{n+1} .
$$

Use of equations (5) and (6) results in equilibrium output and service of

$$
\begin{aligned}
& q_{i}^{*}=\frac{n(A-C)^{2}}{\varphi(n+2)^{2}} \\
& s_{i}^{*}=\frac{A-C}{\varphi(n+2)}
\end{aligned}
$$

Hence the equilibrium price is

$$
P^{*}=\frac{2 A+n C}{n+2}
$$

and the resulting equilibrium profit for firm $i$ is

$$
\pi_{i}^{*}=\frac{n(A-C)^{3}}{\varphi(n+2)^{3}}
$$

As expected, in the limit, as the number of firms increases price is driven to marginal cost, $C$, and profits are driven to zero. Additionally, a cursory glance at (7) and (8) reveals that firm $i$ 's output and service fall as the number of firms increases. These decreases occur as intensifying competition reduces the value of service pro- 
vision, in terms of increased revenue, for a given firm; the costs of service provision cannot be recouped due to the pricing constraints of the competitive market and this leads to reduced service provision. This in turn leads to lower output for a given firm.

\section{Collusion and Welfare Comparisons}

We define collusion as setting output and service levels with the goal of maximizing joint profits. Given that the firms face identical costs of production, the profit function facing any firm engaged in collusion is

$$
\Pi_{i}\left(q_{i}, s_{i}\right)=\left[A-\frac{Q}{S}\right] q_{i}-\left(C+\varphi s_{i}\right) q_{i}, \text { with } Q=\sum_{i=1}^{n} q_{i} \text { and } S=\sum_{i=1}^{n} s_{i}
$$

Each firm will then choose the same level of output and service provision, such that $Q=n q_{i}$ and $S=n s_{i .}$ Using these values in (11) yields

$$
\begin{aligned}
& \Pi_{i}\left(q_{i}, s_{i}\right)=\left[A-\frac{n q_{i}}{n s_{i}}\right] q_{i}-\left(C+\varphi s_{i}\right) q_{i}, \text { which simplifies to } \\
& \Pi_{i}\left(q_{i}, s_{i}\right)=\left[A-\frac{q_{i}}{s_{i}}\right] q_{i}-\left(C+\varphi s_{i}\right) q_{i} . \text { This is the profit function of a sole firm, or }
\end{aligned}
$$

monopolist. This results in the firm's collusive level of output, service, profit, and the market price of $q^{*}{ }_{M}=\frac{(A-C)^{2}}{9 \varphi}, s_{M}{ }_{M}=\frac{A-C}{3 \varphi}, P_{M}{ }^{*}=\frac{2 A+C}{3}$, and $\pi_{M}{ }^{*}=\frac{(A-C)^{3}}{27 \varphi}$.

These values can also be found by using $n=1$ in equations (7) through (10). We use the subscript $M$ to indicate that each firm in the collusive arrangement will produce the monopoly level of output and service while earning the monopolist's level of profit.

The implications for producers are straightforward as participating in the collusive arrangement yields greater profits than engaging in competition. Producer surplus in the competitive case is found by multiplying equation (10) by $n$ resulting in $P S_{\text {comp }}=\frac{n^{2}(A-C)^{3}}{\varphi(n+2)^{3}}$, while producer surplus in collusion is $P S_{\text {collusion }}=\frac{n(A-C)^{3}}{27 \varphi}$.

Producer surplus in the competitive case is maximized with 4 firms in the market; producer surplus in the collusive framework increases linearly as the number of firms increases. ${ }^{6}$ 
The figure below presents producer surplus in the two cases using values of $A=10$ and $C=\varphi=1 .^{7}$

\section{Figure 1.}

\section{Comparison of Producer Surplus}

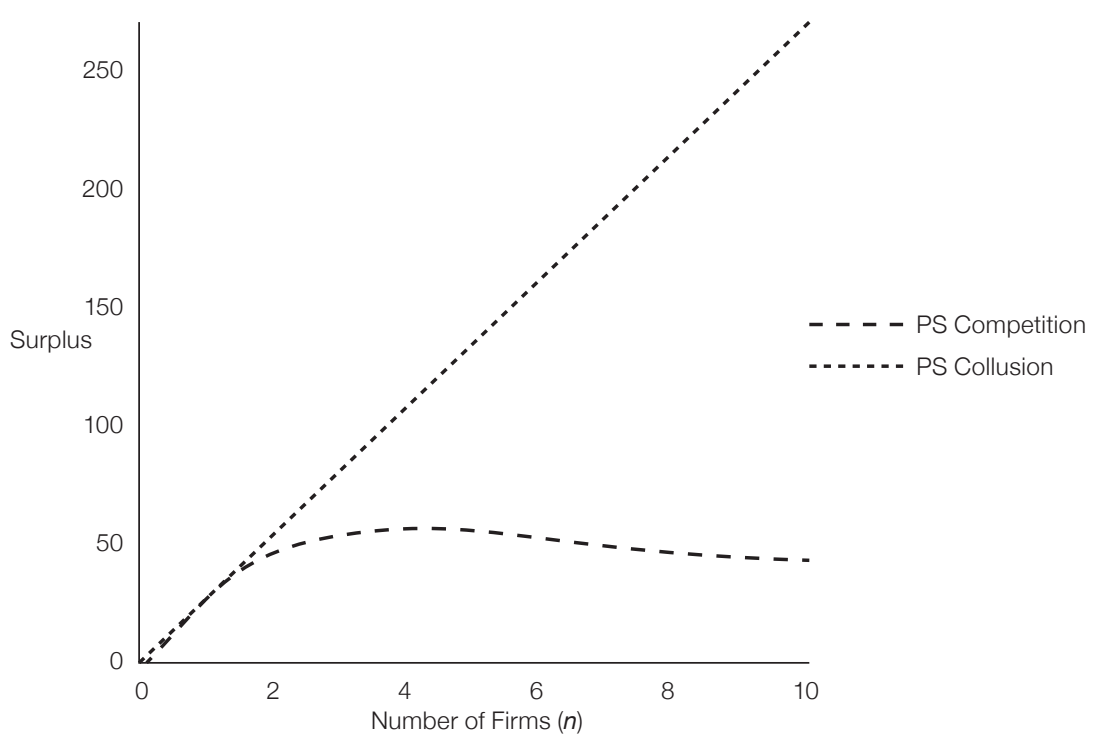

It is evident that the firms are jointly more profitable when colluding for any value of $n \neq 1$.

The effects on consumer welfare are straightforward to discern. Consumer surplus equals $1 / 2\left(A-P^{*}\right) Q^{*}$, where $P^{*}$ is the equilibrium price and $Q^{*}$ is the joint equilibrium output. Use of (7) and (9) results in the competitive consumer surplus of

$$
C S_{\text {comp }}=\frac{n^{3}(A-C)^{3}}{2 \varphi(n+2)^{3}} .
$$

Consumer surplus is a monotonic, concave function in the number of firms, $n$. This follows the usual Cournot result with the minimum consumer surplus occurring with a single monopoly producer. Consumer surplus asymptotically approaches the perfectly competitive market values from below as $n \rightarrow \infty$.

The consumer surplus when the firms are colluding is

$$
C S_{\text {collusion }}=\frac{n(A-C)^{3}}{54 \varphi} \text {. }
$$


A comparison of equations (12) and (13) yields a result of interest. For values of $n>2(5+3 \sqrt{3})$, which is approximately 20.4 firms, the consumer surplus is greater when the firms operate in collusion as opposed to competitively. This is shown in Figure 2 below.

Figure 2

\section{Comparison of consumer surplus}

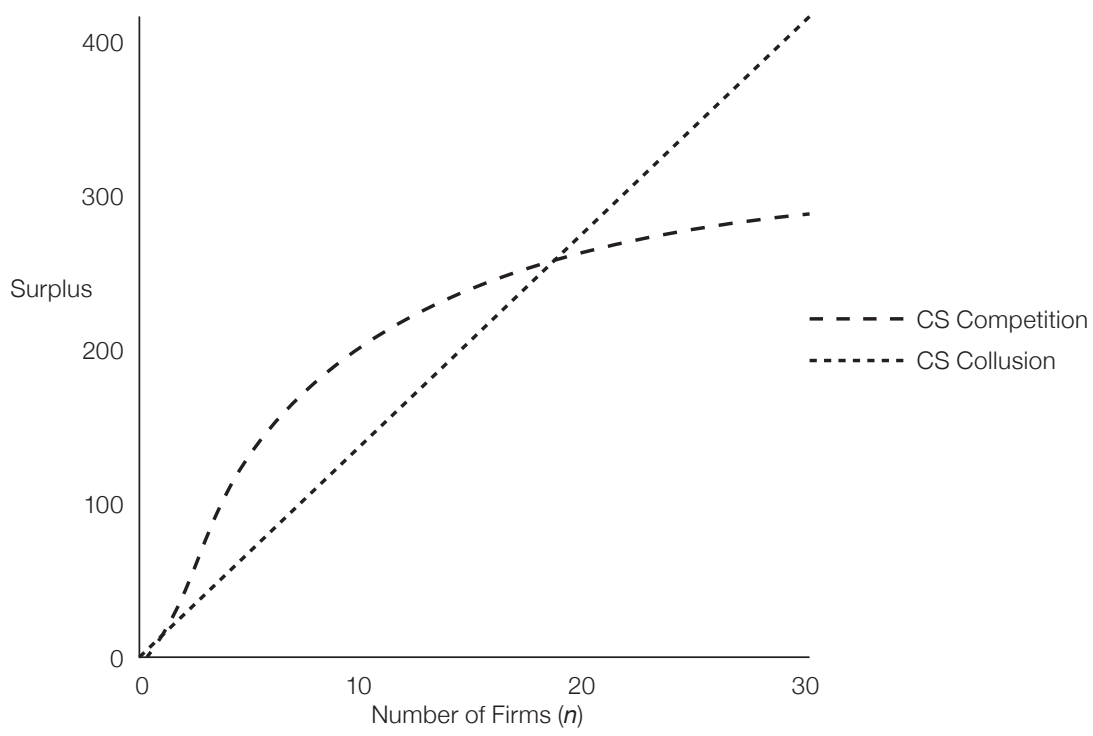

Finally, total surplus in the competitive market is

$$
T S_{\text {comp }}=\frac{n^{2}(A-C)^{3}}{2 \varphi(n+2)^{2}} \text {. }
$$

Similar to consumer surplus, the total surplus asymptotically approaches the perfectly competitive market values from below as $n \rightarrow \infty$.

The total surplus in the collusive market is

$$
T S_{\text {collusion }}=\frac{n(A-C)^{3}}{18 \varphi} \text {. }
$$

A comparison of equations (14) and (15) reveals that for $n>4$ the total surplus in the collusive framework exceeds that of firms engaged in Cournot competition. ${ }^{8}$ This is shown in Figure 3 below. 


\section{Figure 3}

\section{Comparison of Total Surplus}

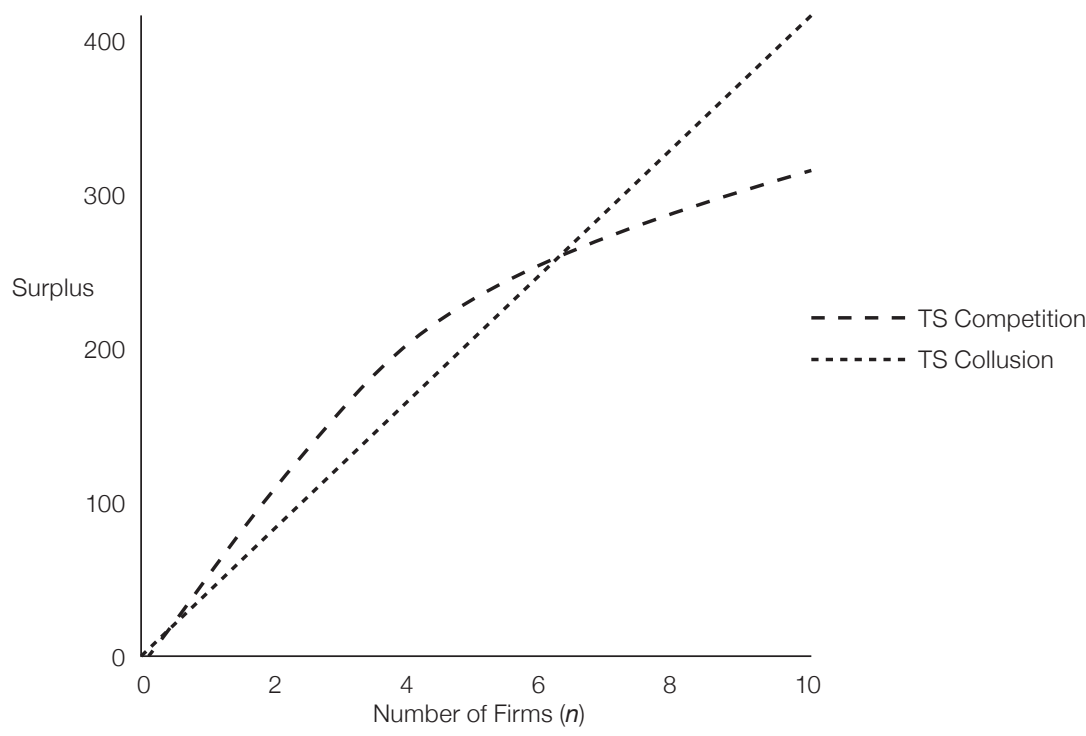

This result is driven by the increases in producer surplus when $n$ is relatively small. For $4<n<2(5+3 \sqrt{3})$, the losses in consumer welfare are more than made up for by the gains to producers. However, both consumers and producers prefer collusion if $n>2(5+3 \sqrt{3})$ as the surplus is greater for each group. This arises as collusion results in greater aggregate levels of service provision relative to the competitive case for a given large number of firms. This encourages marginal consumers to purchase the good, and the effect of this greater service provision on marginal consumers is stronger when there are many firms in the market. ${ }^{9}$

Additionally note that in the limit, as $n \rightarrow \infty$, the total surplus in the competitive framework is $T S_{\text {comp }}=\frac{(A-c)^{3}}{2 \varphi}$, which is the maximum possible value for of this maximum with the total surplus in the collusive arrangement, equation (15), reveals that for $n>9$ the total surplus from collusion exceeds the maximum possible from competition. Note that for $n>4$ the total output in the collusive market exceeds that of $n$ firms engaged in competition. Also the total service level is greater in collusion for $n>3$ versus the competitive case. This relatively large level of service provision induces marginal consumers to enter the market and purchase the product, as the price remains constant in the collusive case. 


\section{Conclusion}

We have developed a theoretical framework to study the profitability of collusion with firms producing homogeneous goods with accompanying service provision. Using a static equilibrium, we show that collusive behavior results in each firm producing the monopoly level of output and service provision; our results indicate that each firm enjoys the monopoly level of profit as well. We have not come across such results in the literature. We show that consumers can benefit from collusion as the number of firms increases beyond $2(5+3 \sqrt{3})$. Additionally, total surplus is greater under collusion if the number of firms exceeds 4 .

We realize that our results may not be particularly robust. The results are likely sensitive to the choice of cost function. Our cost function results in the marginal cost of increasing service provision per unit of output rising with a firm's total production. An alternative specification could separate the cost of service provision from the level of output, such as $T C_{i}=C q_{i}+\varphi s_{i}$. This choice may reflect more accurately the externalities that arise from certain types of service provision, such as promotional messages, and remove the implied scale diseconomy of service provision described above.

However, the nature of our results, welfare enhancing collusion that benefits both consumers and producers with total welfare increasing as the number of firms increases, is unique. There are a variety of avenues for extending this modeling approach. These potential research areas could focus on sequential move play, cost asymmetries, the ability and likelihood of mergers, and/or incentives to cheat on any collusive arrangement. Additionally, more generalization of the demand and cost functions could prove fruitful.

\section{Appendix}

\section{Collusive and competitive results with and alternative demand specification and a brief comparison with the primary results}

This appendix contains the results from firms engaged in Cournot-type competition and profit-maximizing collusion with firms facing the market demand function

$$
P=A-\frac{q_{i}}{s_{i}}-\sum \frac{q_{j}}{s_{j}}
$$

where $q_{j}$ and $s_{j}$ are the output and service levels for any firm $i \neq j$ and the total cost for firm $i$ is $T C_{i}=q_{i}\left(C+\varphi s_{i}\right)$. The results are provided in Table A1 below. 
Table A1

Results with alternative demand specification (A1)

\begin{tabular}{|c|c|c|}
\hline & Collusion & Competition \\
\hline Quantity & $(A-c)^{2}$ & $(A-c)^{2}$ \\
\hline$q_{i}$ & $\overline{n 9 \varphi}$ & $\overline{\varphi(n+2)^{2}}$ \\
\hline Service & $A-c$ & $A-c$ \\
\hline$s_{i}$ & $3 \varphi$ & $\varphi(n+2)$ \\
\hline Price & $2 A+c$ & $2 A+n c$ \\
\hline$P$ & 3 & $n+2$ \\
\hline Profit & $(A-c)^{3}$ & $(A-c)^{3}$ \\
\hline$\pi_{i}$ & $n 27 \varphi$ & $\overline{\varphi(n+2)^{3}}$ \\
\hline Producer & $(A-c)^{3}$ & $n(A-c)^{3}$ \\
\hline Surplus & $27 \varphi$ & $\overline{\varphi(n+2)^{3}}$ \\
\hline Consumer & $(A-c)^{3}$ & $n^{2}(A-c)^{3}$ \\
\hline Surplus & $\overline{54 \varphi}$ & $\overline{2 \varphi(n+2)^{3}}$ \\
\hline Total & $(A-c)^{3}$ & $n(A-c)^{3}$ \\
\hline Surplus & $18 \varphi$ & $\overline{2 \varphi(n+2)^{2}}$ \\
\hline
\end{tabular}

The results of this model follow the traditional results, i.e. in the collusive case the firms each produce a $1 / n$ share of the monopolist's level of output, resulting in constant levels of surplus. It is of some interest to note that the prices and service levels from each case match their counterparts in the primary model. However, the non-cumulative nature of service provision in demand specification (A1) leads to much lower level of output for a given $n$ number of firms. A quick comparison $q^{*}{ }_{i}$ of (equation 7) and $q^{*}{ }_{M}$ with the corresponding results above reveals that output associated with market demand function (1) is $n$ times greater; this is due to the entry of marginal consumers from the associated benefits of cumulative total service provision in this market. 


\section{End Notes}

1. In another arena, Roumanias (2007) finds collusion among corrupt agents increases social welfare as coordination reduces graft.

2. This is not to be confused with a multiproduct oligopoly model, which may arise due to factors such as economies of scope (Bailey \& Friedlander, 1982) in production or product offerings of different quality. The products are assumed to be homogeneous in our model, and the resulting output and service levels are constant across the firms in equilibrium.

3. A potential empirical test for this line of reasoning might involve sales data for each firm selling the product as the number of firms offering the product increases. Our competitive model shows per-firm sales falling while the collusive results indicate constant per-firm sales as the number of firms increases.

4. We thank an anonymous referee for this suggestion.

5. None of these works investigates collusion. Additionally, Boswell and Moore (2009) and Hegji and Moore (2005) focus on duopoly settings while Pepall et al. (2002) focus on the monopoly case.

6. Differentiating $P S_{\text {comp }}$ with respect to $n$ results in $\frac{2 n(A-C)^{3}}{\sigma(n+2)^{3}}-\frac{3 n^{2}(A-C)^{3}}{\sigma(n+2)^{4}}$.

This equals zero for values of $n$ of 4 and 0 . Taking the second derivative of $P S_{\text {comp }}$ with respect to $n$ results in $\frac{2(A-C)^{3}}{\sigma(n+2)^{3}}-\frac{12 n(A-C)^{3}}{\sigma(n+2)^{4}}+\frac{12 n^{2}(A-C)^{3}}{\sigma(n+2)^{5}}$. At $n=4$ this simplifies to $-\frac{(A-C)^{3}}{324 \sigma}$. Hence, $n=4$ satisfies the necessary and sufficient conditions of being a maximum of $P S_{\text {comp }}$.

7. We use values of $\mathrm{A}=10$ and $C=\varphi=1$ for the remaining figures as well.

8. Additionally, similar to Jin's (1996) finding that information sharing should be granted if firms' average squared sales increase, the average squared sales are greater under collusion if $n>4$ versus the competitive outcome.

9. We thank an anonymous referee for noting that equation (5) reveals that a 1 percent increase in service ties with a 2 percent increase in quantity demanded for a 
given firm (firm $i$ ). This relationship aids in indicating the magnitude of increasing marginal consumers as service provision increases.

\section{References}

Bailey, E., \& Friedlander, A. (1982). Market structure and multi-product industries. Journal of Economic Literature, 20.

Boswell, J., \& Moore, E. (2009). Service provision and product differentiation. Journal of Business Strategies, 26(2).

Cellini, R., \& Lambertini, L. (2003). Advertising with spillover effects in a differential oligopoly game with differentiated goods. Central European Journal of Operations Research, 11, 409-423.

Deltas, G., \& Serfes, K. (2002). Semicollusion vs. full collusion: The role of demand uncertainty and product substitutability. Journal of Economics, 77(2), 111-139.

Fershtman, C., \& Pakes, A. (2000). A dynamic oligopoly with collusion and price wars. RAND Journal of Economics, 31(2), 207-236.

Hegji, C., \& Moore, E. (2005). A note on the strategic use of service. Journal of Business Strategies, 22(2), 135-141.

Jin, J. (1996). A test for information sharing in Cournot oligopoly. Information Economics and Policy, 6, 75-86.

Kamien, M., Muller, E., \& Zang, I. (1992). Research joint ventures and R\&D cartels. The American Economic Review, 82(5), 1293-1306.

Pepall, L., Richards, D., \& Norman, G. (2002). Industrial Organization: Contemporary Theory and Practice. Cincinnati, OH: South-Western.

Roumanias, C. (2007). Is collusion of corrupt agents welfare increasing? Economics Letters, 94, 421-425.

Verboven, F. (1995). Corporate restructuring in a collusive oligopoly. International Journal of Industrial Organization, 13, 335-354.

\section{Biographical Sketch Of Authors}

Dr. Moore joined the Department of Economics at Auburn University Montgomery in 2002. He is currently an associate dean for the School of Business. His primary teaching interests are industrial organization, game theory, and microeconomic theory. His primary areas of research include industrial organization and experimental economics. He has published in a variety of journals including the American Economic Review. 
James Boswell joined Booz Allen Hamilton as an operations research analyst in 2009. He provides modeling \& simulation support to Defense and Space industry clients. His research interests include computational statistics, industrial organization, and game theory. James has a B.S. in mathematics from Auburn University Montgomery, and a M.A. in applied economics from Johns Hopkins University. 
